\title{
PREVALENCIA DA DOENÇA DE CHAGAS NO BANCO DE SANGUE DO HOSPITAL DAS CLINIICAS DE GOIĀNIA. POSSIBILIDADE DE FALHA DA REAÇÃo DE GUERREIRO E MACHADO NA SELEÇÃo DE DOADORES *
}

\author{
Cyro Campos **, Jottre Marcondes de Rezende ** e Anis Rassi **
}

Os AA. fazem, inicialmente, breve revisão bibliográfica a respeito do problema da transmissão da doença de Chagas por transfusão de sangue; enfocam aspectos como o alerta dado sobre a possibilidade da ocorrência do fato, confirmação dessa possibilidade no homem, prevalência da infecção chagásica em candidatos à doação em vários Bancos de Sangue e medidas profiláticas adotadas.

No Banco de Sangue do Hospital das Clínicas de Goiânia, observaram que a prevalência da infecção chagásica em candidatos a doadores, avaliada através da reação de Guerreiro e Machado, foi de $10,43 \%$.

Com vistas à verificaçáo da sensibilidade da reação de Guerreiro e Machado na seleção dos candidatos à doação, repetiram o referido exame em 452 doadores, uma ou mais vezes, em diferentes épocas, sempre por ocasião do comparecimento dos mesmos para nova doação. Observaram resultados concordantes da reação em $427(94,47 \%)$ e discordantes em $25(5,53 \%)$.

Ressaltam o risco de se proceder à seleção de doadores de sangue com base na reação de Guerreiro e Machado, mesmo quando repetida mais de uma vez.

Terminam considerando que, no momento, a método ideal de prevenção da transmissão da doença de Chagas por transfusão de sangue é representado pela adição de violeta de genciana a todo e qualquer sangue a ser transfundido, tanto em áreas endêmicas como fora delas, desde que o doador apresente antecedente epidemiológico.

\section{INTRODUÇÃO}

Embora vários autores, sucessivamente, tivessem aventado a possibilidade de trans missão da doença de Chagas por transfusão de sangue $(8,11,17,25,43)$, alguns anos foram decorridos até que estudos específicos sobre o tema fossem encetados.
Com Pellegrino (33) iniciaram se os inquéritos sorológicos em Bancos de Sangue, com vistas à medida da prevalência da infecção chagásica em candidatos a doadores. A partir da observação inicial de Pellegrino, vários inquéritos sorológicos foram realizados em Bancos de Sangue, em nosso país e em outros paises do continente ame-

- Trabalho apresentado no Seminário sobre "Aspectos clínicos de la Enfermedad de Chagas". realizado em Caracas (Venezuela), de 22 a 26 de novembro de 1971, sob auspícics da Organizaçáo Mundial de Saúde.

* Do Departamento de Clínica Médica da Faculdade de Medicina da Universidade Federal de Goiás. Recebido para publicação em 23-1-1975. 
ricano, os quais demonstram a prevalência significativa da positividade da reação de Guerreiro e Machado em individuos aparentemente hígidos, candidatos a doadores de sangue, tanto em áreas endêmicas como fora delas (Quadro I).

Deve-se a Freitas \& cols. (19) o relato das primeiras verificações de transmissão da doença de Chagas ao homem, através da transfusão de sangue; posteriormente, outros autores tiveram oportunidade de fazer observações semelhantes $(3,4,5,6,9,13,16,27,37,42)$.

Através do seguimento de pacientes que haviam recebido sangue proveniente de doadores chagásicos, a transmissão da infec ção foi observada em $18,7 \%$ (27), 13,0\% (42) e $14,3 \%$ (16). Cerisola \& cols. (15) puderam constatar a presença de infecção chagásica em 18 dentre 73 hemofílicos $(24,7 \%)$ que sempre residiram em zonas não endêmicas e que, no transcurso de suas vidas, haviam recebido várias transfusõeõs de sangue; observaram a existência de relação direta entre o número de transfusóes e a positividade sorológica dos receptores.

Levando em conta as dificuldades que se apresentam na seleção rigorosa dos doadores, Nussenzweig \& cols. $(30,31)$ e Nussenzweig \& cols. (29) realizaram uma série de pesquisas, com vistas à obtenção de um agente tripanosomicida, para tratamento, "in vitro", do sangue a ser transfundido, sem alterar-lhe as qualidades. Diversos agentes foram testados, tendo os autores concluído que os melhores resultados foram obtidos com corantes do grupo tri-fenil-metânico, em particular com a violeta de genciana. A violeta de genciana, na concentração de 1:4.000 e após contato de 24 horas, foi capaz de esterilizar o sangue obtido de camundongos infectados pelo $T$. cruzi e revelou-se atóxica em transfuseõs praticadas no homem. Diante dos resultados obtidos, os autores recomendaram que, quando não fosse possível a realização da reação de Guerreiro e Machado em candidatos a doadores suspeitos de apresentarem infecção chagásica, fosse a violeta de genciana adicionada ao sangue, profilaticamente, na concentração de 1:4.000, com tempo de contato mínimo de 24 horas antes de seu emprego.

A eficácia da violeta de genciana na profilaxia da transmissão da doença de Chagas por transfusões de sangue foi apurada por Nussenzweig \& cols. (27), Amato Neto \& Mellone (7) e Nussenzweig \& cols. (28), através do seguimento parasito-sorológico de indivíduos que receberam transfusōes de sangue proveniente de doadores chagásicos, ao qual foi adicionado o corante previamente. Em nen'hum receptor puderam constatar transmissão da infecção.

À medida em que eram processados inquéritos sorológicos em Bancos de Sangue, ènfase ia sendo dada quanto à necessidade da adoção de medidas profiláticas, tanto em áreas endêmicas como fora delas, em razão do movimento migratório das populações. Estavam representadas por duas alternativas: seleção dos candidatos a doadores através da reação de Guerreiro e Machado e adição prévia de violeta de genciana ao sangue a ser transfundido.

A reação de Guerreiro e Machado foi dada importância capital: se negativa, 0 sangue seria desprezado ou usado após seu tratamento com violeta de genciana; se não pudesse ser realizada e se a área endêmica estivesse em jogo, dever-se-ia adicionar 0 corante a todo sangue a ser transfundido.

Entretanto, a realização da reação de Guerreiro e Machado não deve oferecer a segurança necessária na seleção dos doado. res, sobretudo quando executada uma só vez, por não detectar a totalidade dos chagásicos, uma vez que sua sensibilidade máxima é de $98,5 \%$ (18) quando perfeitamente executada, o que nem sempre ocorre, e porque pode resultar transitoriamente negativa, conforme demonstraram Rassi \& cols. (36), ao praticarem-na, reiteradamente, num grupo de chagásicos.

Com efeito, Jatene \& Jacomo, em 1955 (22), no Banco de Sangue de Uberaba, encontraram 5 dentre 101 doadores com a reação de Guerreiro e Machado negativa no primeiro exame e positiva no exame seguinte, realizado 40 dias a 8 meses depois, "sem a possibilidade de a doença ter sido adquirida neste período". Deram a conhecer a conduta seguida em dois Bancos de Sangue, um em Uberlândia (Dr. J. B. Ribeiro) e outro em Araguari (Dr. H. Vaz), nos quais a violeta de genciana vinha sando usada de maneira sistemática desde 2 anos antes e concluíram que, nas áreas de alta endemicidade, somente o uso do co. rante em todo sangue a ser transfundido representaria medida profilática realmente 


\section{QUADRO I}

POSITIVIDADE DA REAÇAO SOROLÓGICA PARA DOENÇA DE CHAGAS EM CANDIDATOS A DOADORES DE SANGUE, SEGUNDO DIVERSOS AUTORES

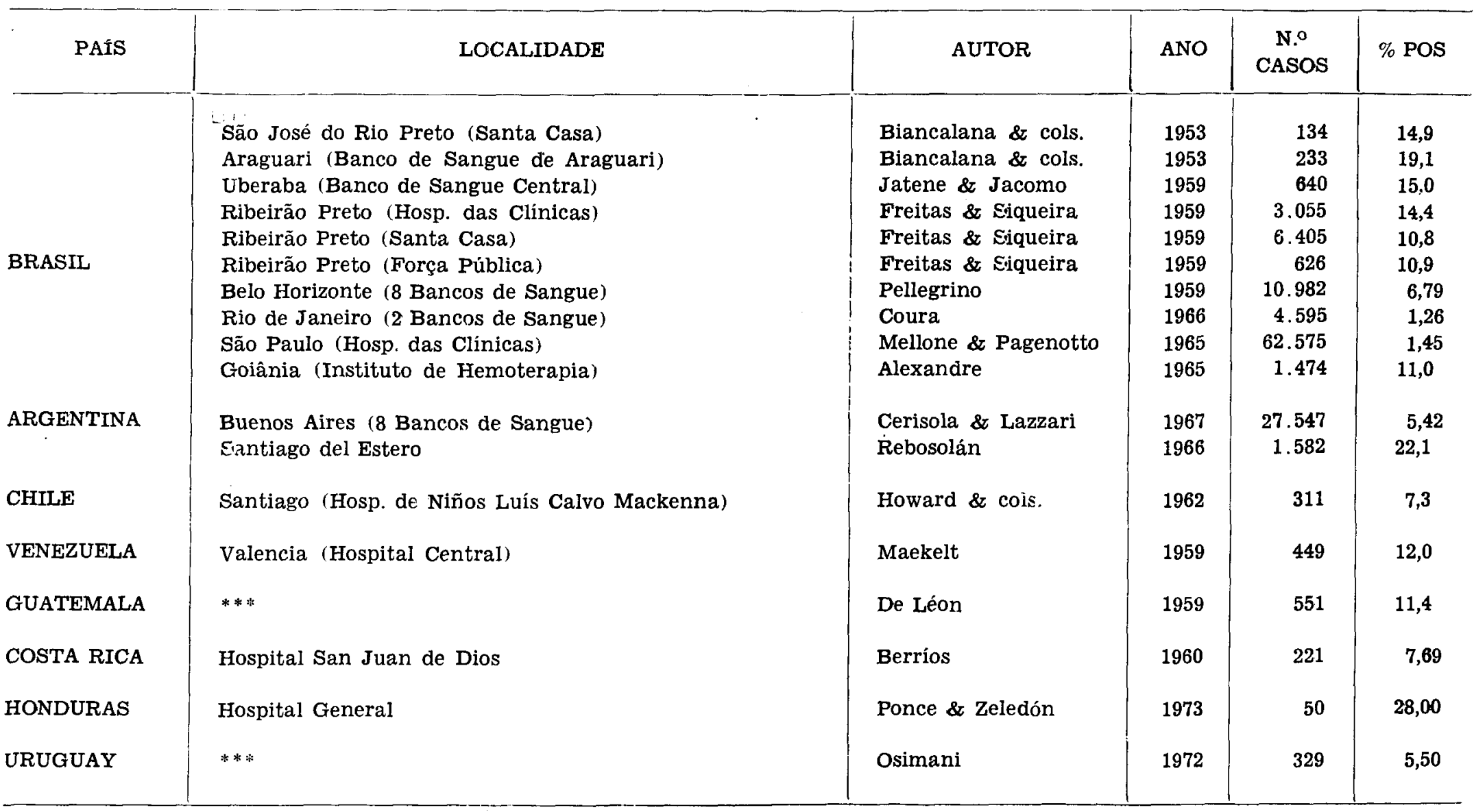


eficaz; essa rotina foi adotada por alguns outros Bancos de Sanglie, com ótimos resultados (40), apresentando, ainda, as vantagens de tornar desnecessária a realização do exame sorológico e de possibilitar o aproveitamento de boa quantidade de sangue que, de outra forma, seria desprezada.

A inocuidade da violeta de genciana foi referida por Nussenzweig \& cols. (27), Jatene \& Jacomo (22) e, mais detalhadamente, por Rezende \& cols. (40). Com efeito, estes últimos autores relataram a experiência do Banco de Sangue do Hospital das Clínicas da Faculdade de Medicina da U.F.Go (ao tempo chamado de Hospital Geral de Goiânia), no qual foram realizadas 2.973 trans. fusões de sangue com violeta de genciana, na concentração de 1:4.000, em 774 pacientes; a quantidade máxima transfundida em um mesmo paciente foi de $36.000 \mathrm{ml}$, no total de 74 transfusões durante 6 meses e a quantidade máxima transfundida de uma só vez foi de $4.000 \mathrm{ml}$; nenhum receptor apresentou efeitos tóxicos, sendo que todos os pacientes que, por causas diversas, vieram a falecer, em número de 55 , foram necropsiados, não sendo constatadas impregnações de tecidos, flebites ou outras alterações imputáveis ao corante.

No presente trabalho investigamos a prevalência da doença de Chagas em candidatos à doação de sangue, bem como o valor da reação de Guerreiro e Machado na seleção dos mesmos.

\section{MATERIAL E MÉTODOS}

Entre março de 1962 a junho de 1971, 12.603 doadores fizeram 18.582 doações de sangue no Banco de Sangue do Hospital das Clínicas da Faculdade de Medicina da Universidade Federal de Goiás, em Goiânia. Dado que as internações nesse Hospital são condicionadas à doação de sangue, muitos doadores são familiares dos pacientes ou pessoas de seu relacionamento. São também utilizados voluntários, destacando-se, dentre eles, reclusos do Centro Penitenciário de Atividade Industrial do Estado de Goiás (CEPAIGO) e militares da Polícia Militar do Estado de Goiás e do $10 .^{\circ}$ Batalhão de Caçadores do Exército Brasileiro, com sede em Goiânia.

$\mathrm{Na}$ seleção dos candidatos o exame clínico é bastante sumário, sendo recusados aqueles com passado de icterícia ou de malária.

Todo e qualquer sangue é colhido em frascos contendo violeta de genciana (1:4.000) juntamente com a solução $\mathrm{ACD}$, sendo o mesmo utilizado somente após permanência na geladeira durante o mínimo de 24 horas e independentemente do resultado da reação de Guerreiro e Machado.

A reação de Guerreiro e Machado é repetida toda vez que o candidato retorna para nova doação e é praticada pela técnica de gotas sobre placas (2), usando-se antígeno metílico.

\section{RESULTADOS}

A reação de Guerreiro e Machado foi realizada em 4.819 doadores, dos quais 447 apresentaram soro anti-complementar ou resultado duvidoso, tendo sido excluídos do presente estudo. Dos 4.372 doadores restantes (Quadro II), a reação foi negativa em $3.916(89,57 \%)$ e positiva em 456 $(10,43 \%)$.

A reação foi repetida uma ou mais vezes, em datas diferentes, em 452 doadores (Quadro III), com resultados concordantes em $427(94,47 \%)$ e discordantes em 25 $(5,53 \%)$. Destes 452 doadores, 351 realizaram duas reações, 80 três reações, 18 quatro reações e 3 cinco reações; houve 18 resultados divergentes $(5,1 \%)$ no grupo com

\section{QUADRO II}

Resultados da reação de Guerreiro e Machado praticada em 4.372 doadores de sangue não selecionados

(Hospital das Clínicas da FM da UFGo)

\begin{tabular}{l|c|c}
\hline Resultado * & N.o de casos & $\%$ \\
\hline Positivo & 456 & 10,43 \\
Negativo & 3.916 & 89,57 \\
\hline
\end{tabular}

* Foram exclufalas as reaçóes anticomplementares e duvidosas. 


\section{QUADRO III}

Resultados da reação de Guerreiro e Machado praticada duas a quatro vezes no mesmo doador, em épocas diferentes

(Hospital das Clínicas da FM da UFGo)

\begin{tabular}{l|c|c|c|c}
\multicolumn{1}{c|}{ Resultados } & N.o de casos & $\%$ & $\begin{array}{c}\text { Total } \\
\text { de } \\
\text { casos }\end{array}$ & $\begin{array}{c}\text { Total } \\
\text { de } \\
\text { reações }\end{array}$ \\
\hline Concordantes & 427 & 94,47 & & \\
Discordantes & 25 & 5,53 & & 1.029 \\
\hline
\end{tabular}

\section{QUADRO IV}

Resultados discordantes da reação de Guerreiro e Machado quando praticada duas vezes no mesmo doador, em épocas diferentes

Hospital das Clínicas da FM da UFGo

\begin{tabular}{|c|c|c|c|}
\hline N. ${ }^{\circ}$ Ficha & Doador & \multicolumn{2}{|c|}{ Resultados } \\
\hline 3.534 & C.E.P. & $\begin{array}{c}\text { Negativa } \\
26.09 .66\end{array}$ & $\begin{array}{c}\text { POSITIVA } \\
11.10 .66\end{array}$ \\
\hline 3.558 & N.B.S. & $\begin{array}{c}\text { Negativa } \\
23.05 .69\end{array}$ & $\begin{array}{c}\text { POSITIVA } \\
03.11 .69\end{array}$ \\
\hline 3.567 & J.P.S. & $\begin{array}{c}\text { Negativa } \\
12.09 .66\end{array}$ & $\begin{array}{c}\text { POSITIVA } \\
24.06 .69\end{array}$ \\
\hline 4.696 & F.R. & $\begin{array}{c}\text { Negativa } \\
20.08 .66\end{array}$ & $\begin{array}{c}\text { POSITIVA } \\
29.05 .69\end{array}$ \\
\hline 5.658 & D.F. & $\begin{array}{c}\text { Negativa } \\
19.01 .68\end{array}$ & $\begin{array}{c}\text { POSITIVA } \\
25.08 .70\end{array}$ \\
\hline 7.987 & J.R.S. & $\begin{array}{c}\text { Negativa } \\
18.07 .68\end{array}$ & $\begin{array}{c}\text { POSITIVA } \\
04.03 .69\end{array}$ \\
\hline 8.073 & J.R.O. & $\begin{array}{c}\text { Negativa } \\
29.07 .68\end{array}$ & $\begin{array}{c}\text { POSITIVA } \\
25.10 .68\end{array}$ \\
\hline
\end{tabular}




\begin{tabular}{|c|c|c|c|}
\hline N. ${ }^{\circ}$ Ficha & Doador & \multicolumn{2}{|c|}{ Resultados } \\
\hline 8.317 & J.S.F. & $\begin{array}{c}\text { Negativa } \\
12.09 .68\end{array}$ & $\begin{array}{c}\text { POSITIVA } \\
06.05 .69\end{array}$ \\
\hline 86 & M.R. & $\begin{array}{c}\text { POSITIVA } \\
17.10 .66\end{array}$ & $\begin{array}{c}\text { Negativa } \\
01.04 .69\end{array}$ \\
\hline 801 & N.J.A. & $\begin{array}{c}\text { POSITIVA } \\
09.03 .68\end{array}$ & $\begin{array}{c}\text { Negativa } \\
18.08 .69\end{array}$ \\
\hline 1.965 & $\mathbf{S . V . S . ~}$ & $\begin{array}{c}\text { POSITIVA } \\
29.07 .68\end{array}$ & $\begin{array}{c}\text { Negativa } \\
16.07 .70\end{array}$ \\
\hline 4.517 & T.S.G. & $\begin{array}{c}\text { POSITIVA } \\
04.07 .66\end{array}$ & $\begin{array}{c}\text { Negativa } \\
30.11 .68\end{array}$ \\
\hline 4.673 & M.V.S. & $\begin{array}{c}\text { POSITIVA } \\
16.08 .66\end{array}$ & $\begin{array}{c}\text { Negativa } \\
14.10 .67\end{array}$ \\
\hline 5.520 & M.A. & $\begin{array}{c}\text { POSITIVA } \\
22.11 .67\end{array}$ & $\begin{array}{c}\text { Negativa } \\
23.09 .68\end{array}$ \\
\hline 7.133 & N.C.A. & $\begin{array}{c}\text { POSITIVA } \\
17.01 .68\end{array}$ & $\begin{array}{c}\text { Negativa } \\
13.08 .70\end{array}$ \\
\hline 9.791 & J.G.L. & $\begin{array}{c}\text { POSITIVA } \\
04.06 .69\end{array}$ & $\begin{array}{l}\text { Negativa } \\
11.09 .69\end{array}$ \\
\hline 9.824 & E.R. & $\begin{array}{c}\text { POSITIVA } \\
10.06 .69\end{array}$ & $\begin{array}{c}\text { Negativa } \\
13.09 .69\end{array}$ \\
\hline 10.914 & W.s. & $\begin{array}{c}\text { POSITIVA } \\
09.07 .70\end{array}$ & $\begin{array}{c}\text { Negativa } \\
04.09 .70\end{array}$ \\
\hline
\end{tabular}

duas reações, $5(6,2 \%)$ no grupo com três reaçōes e $2(11,1 \%)$ no grupo com quatro reaçōes (Quadros IV, V e VI). Não houve resultados discordantes no pequeno grupo com cinco reaçōes. Em nenhum dos casos em que a reação resultou inicialmente negativa houve possibilidade do doador ter adquirido a infecção $\mathrm{em}$ seguida.

\section{COMENTARIOS}

A p̣revalência da doença de Chagas em doadores de sangue no Hospital das Clínicas de Goiânia foi de $10,43 \%$, percentual inferior ao encontrado em Bancos de Sangue de outras áreas endêmicas e também inferior à prevalência da doença de Chagas entre pacientes não selecionados, internados no Hospital das Clínicas nesse mesmo período, cujo resultado foi de $24,75 \%$ (39). Tal fato é compreensível se levarmos em conta a predominância de doadores procedentes de zona urbana em nosso material.

Nossas verificaçōes comprovam o risco de se proceder à seleção de doadores com base em uma, ou mesmo mais reaçóes de Guerreiro e Machado. Em parte, o óbice poderia ser contornado pela prática simul. tânea de outras provas sorológicas, como a imunofluorescência e a hemaglutinação, com vistas ao aumento da sensibilidade do diagnóstico sorológico.

Se por um lado considerarmos a possibilidade de falha no diagnóstico sorológico 


\section{QUADRO V}

Resultados discordantes da reação de Guerreiro e Machado quando praticada três vezes no mesmo doador, em épocas diferentes

(Hospital das Clínicas da FM da UFGo)

\begin{tabular}{|c|c|c|c|c|}
\hline N.o Ficha & Doador & \multicolumn{3}{|c|}{ Resultados } \\
\hline 674 & F.E.S. & $\begin{array}{c}\text { POSITIVA } \\
31.08 .66\end{array}$ & $\begin{array}{l}\text { Negativa } \\
11.01 .67\end{array}$ & $\begin{array}{c}\text { POSITIVA } \\
18.05 .67\end{array}$ \\
\hline 1.459 & V.B.M. & $\begin{array}{c}\text { Negativa } \\
19.06 .68\end{array}$ & $\begin{array}{c}\text { Negativa } \\
13.09 .68\end{array}$ & $\begin{array}{c}\text { POSITIVA } \\
12.06 .69\end{array}$ \\
\hline 3.815 & H.H.S. & $\begin{array}{c}\text { POSITIVA } \\
07.03 .69\end{array}$ & $\begin{array}{c}\text { Negativa } \\
19.03 .69\end{array}$ & $\begin{array}{c}\text { POSITIVA } \\
25.03 .69\end{array}$ \\
\hline 4.255 & C.T.M. & $\begin{array}{c}\text { Negativa } \\
13.05 .68\end{array}$ & $\begin{array}{c}\text { POSITIVA } \\
19.07 .68\end{array}$ & $\begin{array}{c}\text { POSITIVA } \\
27.10 .68\end{array}$ \\
\hline 9.385 & O.N. & $\begin{array}{c}\text { Negativa } \\
02.04 .69\end{array}$ & $\begin{array}{c}\text { POSITIVA } \\
02.10 .69\end{array}$ & $\begin{array}{c}\text { Negativa } \\
05.05 .70\end{array}$ \\
\hline
\end{tabular}

QUADRO VI

Resultados discordantes da reação de Guerreiro e Machado quando praticada quatro vezes no mesmo doador, em épocas diferentes

(Hospital das Clínicas da FM da UFGo)

\begin{tabular}{|c|c|c|c|c|c|}
\hline N. ${ }^{\circ}$ Ficha & Doador & \multicolumn{4}{|c|}{ Resultados } \\
\hline 1.559 & A.A.S. & $\begin{array}{c}\text { POSITIVA } \\
14.08 .67\end{array}$ & $\begin{array}{c}\text { Negativa } \\
02.02 .68\end{array}$ & $\begin{array}{c}\text { Negativa } \\
12.08 .68\end{array}$ & $\begin{array}{c}\text { Negativa } \\
10.04 .69\end{array}$ \\
\hline 2.028 & O.J.M. & $\begin{array}{c}\text { Negativa } \\
01.07 .68\end{array}$ & $\begin{array}{c}\text { Negativa } \\
12.09 .68\end{array}$ & $\begin{array}{c}\text { Negativa } \\
18.11 .68\end{array}$ & $\begin{array}{c}\text { POSITIVA } \\
29.04 .69\end{array}$ \\
\hline
\end{tabular}

da doença de Chagas e, por outro, a eficácia e a inocuidade da violeta de genciana, torna-se óbvio que a adição do referido corante a todo e qualquer sangue destinado à transfusão, tanto em áreas endêmicas como fora delas, desde que o doador apresente antecedente epidemiológico, constitui, no momento, o método ideal de prevenção da transmissão da doença de Chagas por transfusão de sangue. 


\section{SUMMARY}

Initially the authors review the bibliography concerning problems of transmission of Chagas' disease through blood transfusion. Emphasis is given to the various aspects to call attention to the possible occurence of this fact. The confirmation of this possibility in man, the high incidence of chagasic infection in blood donors found in various blood banks and the prophylactic methods that should be adopted are discussed.

At the blood bank of the Hospital das Clinicas in Goiânia, the prevalence of chagasic infection has been observed in blood donors and evaluated through the Guerreiro and Machado test at 10,43\%.

With the finality to verify the sensibility of the Guerreiro and Machado reaction in the selection of blood donors, the examination was repeated in 452 donors, once or more, in different times, when the various blood donors would come again to donate blood. Concording results were observed in the reaction of $427(94,47 \%)$ and discording results in $25(5,53 \%)$.

The authors emphasize the risk involved in the selection of blood donors using the Guerreiro and Machado test as a safeguard even when it has been repeated more than once.

Finaly, the authors consider that at the present time the ideal method to prevent the transmission of Chagas' disease through blood transfusion is the addition of gentian violet to any blood to be transfused, in endemic areas as in other areas, whenever the donor might have epidemiologic antecedent.

\section{REFERÊNCIAS BIBLIOGRÁFICAS}

1. ALEXANDRE, A. - Comunicação pessoal, 1964. Apud REZENDE, J. M. de \& cols. (36) .

2. ALMEIDA. J. O. de - Reação quantitativa de fixação do complemento em gotas sobre placas, pelo método das curvas iso-hemolíticas. Rev. Inst. Med. Trop. Sấo Paulo, 5: 176-189, 1963.

3. AMATO Neto, V. - Contribuição ao conhecimento da forma aguda da doença de Chagas. São Paulo, Tip. Edanee - 1958. 332 p. Tese, Fac. Med. Inniv. São Paulo.

4. AMATO Neto, V. \& DIAS, A. F. - Comentários sobre caso de transmissão da doença de Chagas por transfusão de sangue e longo período de incuba. cão. Rev. Soc. Bras. Med. Trop., 3: 273-275, 1969.

5. AMATO Neto, V.; DOLES, J.: RASSI, A.; BORGES, A. de P.; REZENDE, J. M. de \& GOMES, M. C. de O. - Relato de novos casos de transmissão da doença de Chagas por transfusāo de sangue. Rev. Inst. Med. Trop. São Paulo, 10: 46-51, 1968.
6. AMATO Neto, V.; MAGALDI, C. \& BIANCHI, A. - Comprovação de mais um caso de transmissão da doença de Chagas por transfusão de sangue. $O$ Hospital, 64: 123-130, 1963.

7. AMATO Neto, V. \& MELLONE, O. Estudo sobre a eficácia da violeta de genciana na profilaxia da transmissão da doença de Chagas em bancos de sangue: investigação em voluntário, receptor de sangue de caso agudo, ao qual foi adicionado o corante. $O$ Hospital, 55: 343-346, 1959.

8. BACIGALUPO, J. - Enfermedad de Chagas y transfusión sanguínea. $E l$ Día Méd., 20: 425-426, 1948.

9. BERGOGLIO, R. M. - Enfermedad de Chagas post-transfusional. Rev. Méd. C'órdoba, 53: 266-271, 1965. Apud ROHWEDDER, R. W. (41).

10. BERRíos, A. - Investigaciones sobre enfermedad de Chagas en Costa Rica por la reacción de fijación del complemento. Rev. Biol. Trop., 8: 203-217, 1960. 
11. BERTÍN, V. - Consideraciones sobre la epidemiología de la enfermedad de Chagas en Chile y su profilaxis. BolMed. Soc., 7: 565-634, 1940. Apud ROHWEDDER, R. W. (41).

12. BIANCALANA, A.; FREITAS, J. L. P. de; AMATO Neto, V.; NUSSENZWEIG, V. \& SONNTAG, R. - Investigações sorológicas sobre doença de Chagas entre candidatos a doadores em Bancos de Sangue nos Estados de São Paulo e Minas Gerais. O Hospital, 44: 745-749, 1953.

13. CAMARGO, M. E. \& LESER, P. G. Diagnóstico acidental de laboratório de infecções chagásicas agudas pós-transfusionais não suspeitadas. Rev. Ass. Med. Brasil., 20: 335-336, 1974.

14. CERISOLA, J. A. \& LAZZARI, J. O. La transmisión de la enfermedad de Chagas por la tranfusión de sangre. Seg. Jorn. Entomoepid. Arg., 1: 203207, 1967.

15. CERISOLA, J. A.; RABINOVICH, A.; ALVAREZ, M., Di CORLETO, C. A. \& PRUNEDA, J. - Enfermedad de Chagas y la transfusion de sangre. Separata. Reimp. Bol. Of. Sanit. Panamer., 63: 203-221, 1972.

16. COUR.A. .T. R. - Contribuiç̃o ao estudo da doença de Chagas no Estado da Guanabara. Rev. Brasil. Malar. Doenças Trop., 18: 9-98, 1966.

17. DIAS, E. - Um ensaio de profilaxia de moléstia de Chagas. Rio de Janeiro, Imprensa Nacional, 1945, $116 \mathrm{p}$.

18. FREITAS, J. L. P. de - Reação de fixação do complemento para diagnóstico da moléstia de Chagas pela técnica quantitativa. Arq. Hig. Saúde Publ., 16: 55-94, 1951.

19. FREITAS, J. L. P. de; BIANCALANA, A.; AMATO Neto, V.; NUSSENZWETG, V., SONNTAG, R. \& BARRETO, J. G. Primeiras verificações de transmissão acidental da moléstia de Chagas ao homem por transfusão de sangue. Rev. Faulista Med., 40: 36-40, 1952.

20. FREITAE;, J. L. P. de \& SIQUEIRA, A. F. de - Prevalência da infecção chagásica entre candidatos a doadores de sangue e entre outros grupos na cidade de Ribeirão Preto, Estado de São Paulo. In Resumos trabalhos apresentados Cong. Internac. sobre Doença de Chagas, Rio de Janeiro, 1959. p. 20.

21. HOWARD, J.; RUBIO, M.; KNIERIM, F. \& HUIDOBRO, J. G. - Investiga- ción de infección trypanosómica ( $T$. cruzi) em doadores del Banco de Sangre del Hospital de Niños "Luis Calvo Mackenna".Bol. Chileno Parasit., 17: $29,1962$.

22. JATENE, A. D. \& JACOMO, R. Doença de Chagas e transfusāo de sangue. Rev. Goiana Med., 5: 23-30, 1959.

23. LEON, J. R. de - Estado actual de la enfermedad de Chagas en Guatemala; resumen epidemiológico. Rev. Goiana Med., 5: 445-455, 1959.

24. MAEKELT, G. A. - Contribución para el estudio de la enfermedad de Chagas en Venezuela. Investigaciones serológicas de la enfermedad de Chagas mediante la reacción de fijación del complemento. Arch. Venezolanos Med. Trop. Parasit. Med., 3: 252-271, 1959.

25. MAZZA, S.; MONTAÑA, A.; BENITEZ, C. \& JANZI, E. Z. - Transmisión del Schizotrypanum cruzi, al niño por leche de la madre con enfermedad de Chagas. Public M.E.P.R.A., 28: 41-46, 1936.

26. MELLONE, O. \& PAGENOTTO, J. Incidência de sorologia positiva para sífilis e doença de Chagas em 62.575 doadores de sangue. Rev. Hosp. Clin. Fac. Med. São Faulo, 20: 165-167, 1965.

27. NUSEENZWEIG, V.; AMATO Neto, V.; FREITAS, J. L. P. de; NUSSENZ WEIG, R. S. \& BIANCALANA, A. Moléstia de Chagas em Bancos de Sangue. Rev. Hosp. Clín., 10: 265-283, 1955.

28. NUSFENZWEIG, V.; AMATO Neto, V. \& MELLONE, O. - Novos dados sobre - emprego da violéta de genciana na profilaxia da transmissão da doença de Chagas por transfusão de sangue. O Hospital, 55: 183-188, 1953.

29. NUSSENZWEIG, V.; NUSEENZWEIG, R. S.; FREITAS, J. L. P. de; AMATO Neto, V.; BIANCALANA, A. \& KLOETZEL, J. - Ação de agentes físicos e químicos sobre o Trypanosoma cruzi "in vitro". O Hospital, 45: 589-599, 1954.

30. NUSSENZWEIG, V.; SONNTAG, R.; BIANCAL.ANA. A., FREITAS, J. L. P. de; AMATO Neto, V. \& KLOETZEL, J. - Ação da violeta de genciana sobre o $T$. cruzi in vitro: sua importância na esterilização do sangue destinado à transfusão. Rev. Paulista. Med., 42: 57-58, 1953. 
31. NUSSENZWEIG, V.; SONNTAG, R., BIANCALANA, A.; FREITAS, J. L. P. de; AMATO Neto, V. \& KLOETZEL, J. - Ação de corantes tri-fenil-metânicos sobre o Tripanosoma cruzi "in vitro". Emprego da violeta de genciana na profilaxia da transmissão da moléstia de Chagas por transfusão de sangue. O Hospital, 44: 731-744, 1953a.

32. OSIMANI, J. J. - Epidemiologia de la enfermedad de Chagas en Uruguay. In Simposio Internacional sobre enfermedad de Chagas. Buenos Aires Div. Imprenta Secretaria Salud Pública de la Nación. 1972. pp. 209-215.

33. PELLEGRINO, J. - Transmissão da doença de Chagas pela transfusão de sangue. Primeiras comprovações sorológicas em doadores e candidatos a doadores de sangue. Rev. Brasil. Med., 6: 297-301, 1949.

34. PELLEGRINO, J. - Doença de Chagas e transfusão de sangue. Rev. Brasil. Malar. Doenças Trorp., 11: 697706, 1959.

35. PONCE, C. \& ZELEDÓN, R. - La enfermedad de Chagas en Honduras. Bol. Of. Sanit. Panamer., 75: 239-249, 1973.

36. RASSI, A.; AMATO Neto, V. \& SIQUEIRA, A. F. de - Comportamento evolutivo da reação de fixação do complemento na fase crônica da moléstia de Chagas. Rev. Inst. Med. Trop. Sâo Paulo, 11: 430-435, 1969.

37. RASSI, A. \& FERRETRA, H. de O. - Tentativas de tratamento especifi- co da fase aguda da doença de Chagas com nitrofuranos em esquemas de duração prolongada. Rev. Soc. Bras. Med. Trop., 5: 235-262, 1971.

38. REBOSOLÁN, J. B. - Estado actual de la enfermedad de Chagas-Mazza en Santiago del Estero. La Prensa Méd. Argentina, 53: 1327-1330, 1966. Apud ROHWEDDER, R. W. (41).

39. REZENDE, J. M. de - Anestesiologia face à patologia do Brasil .Central Rev. Goiana Med., 17: 100-101, 1971.

40. REZENDE, J. M. de; ZUPELLI, W. \& BAFUTTO, M. G. - O problema da transmissão da doença de Chagas por transfusão de sangue. Emprego da violeta de genciana como medida profilática. Rev. Goiana Med., 11: 35-47, 1965.

41. ROHWDDER, R. W. - Infección chagásica en dadores de sangre y las pro babilidades de transmitirla por medio de la transfusión. Bol. Chileno Parasit., 24: $88-93,1969$.

42. SALAZAR H., J. ARENDS, T. \& MAEKELT, G. A. - Comprobación en Venezuela de la transmisión del Schizo trypanum cruzi por transfusión de sangre. Arch. Venezolanos Med. Trop. Parasit. Med., 4: 355-363, 1962.

43. TALICE, R. V. - Enfermedades para sitarias y transfusión de sangre (sangre y derivados). Curso de Hemoterapia, pp. 135-144. A pud ROHWEDDER, R. W. (41). 